\title{
Assessment of Genetic Polymorphisms in DNA from Formalin Fixed Neurological Tissues
}

\author{
M. Mortilla, G. Vaula and P.H. St George-Hyslop
}

\begin{abstract}
The ability to analyze the genotype of deceased affected members of pedigrees segregating inherited neurological diseases considerably augments the informativeness of such pedigrees. This information has direct application in attempts to isolate disease genes by positional cloning strategies, and for genetic counselling. We show that the genotype at polymorphic simple sequence repeat loci can be determined from genomic DNA isolated from 10 micron thick paraffin embedded, formalin fixed neurological tissues. The critical constraint on this method is the size of the template target bearing the simple sequence repeat, which should ideally be less than 165 base pairs.
\end{abstract}

\begin{abstract}
Résumé: Évaluation de polymorphismes génétiques d'ADN provenant de tissus nerveux fixés par la formaline. La capacité d'analyser le génotype de membres atteints décédés de familles où ségrèguent des maladies neurologiques héréditaires augmente considérablement l'informativité de tels arbres généalogiques. Cette information a une application directe à l'isolation de gènes anormaux par des stratégies de clonage positionnel et pour le conseil génétique. Nous démontrons que le génotype peut être déterminé au niveau de sites polymorphiques constitués de séquences répétitives simples à partir d'ADN génotique isolé d'échantillons de tissus nerveux de 10 microns d'épaisseur fixés à la formaline et inclus dans la paraffine. L'élément critique dans cette méthode est la taille de la séquence répétitive ciblée qui, idéalement, devrait être inférieure à 165 paires de bases.
\end{abstract}

Can. J. Neurol. Sci. 1994; 21: 248-251

A growing number of human neurologic disorders with onset in adult life are now known to have either a purely genetic etiology, or to have a genetic component to their etiology. ${ }^{1}$ Recent efforts to map the human genome, and recent advances in statistical analysis of pedigree data for both simple and complex traits suggest that it should theoretically be possible to map and eventually isolate the genetic defects responsible for susceptibility to many of these diseases.

A major limitation to this approach arises from the fact that many of the adult onset inherited neurologic diseases either considerably shorten the life expectancy of affected individuals or have the onset of symptoms very late in life. The resulting sub-optimal structure of disease pedigrees hampers attempts both to isolate the actual disease gene and to predict genetic risk amongst at-risk family members. ${ }^{2}$ However, tissue specimens have frequently been collected at diagnostic biopsy or postmortem studies from deceased affected members in preceding generations of many pedigrees with late onset inherited neurological disorders. We report that DNA extracted from formalinfixed, paraffin-embedded neuropathology specimens can be analyzed for informative simple sequence repeat (SSR) polymorphisms (also known as microsatellite or simple tandem repeat polymorphisms).

\section{Methods and Materials}

\section{Source of tissues}

Formalin fixed, paraffin embedded tissue specimens were obtained from brain tissue of eight patients dying with Alzheimer Disease (AD). The brain tissue had been fixed in buffered neutral formalin for at least ten days, embedded in paraffin, and stored at room temperature for five to fifteen years. For one subject genomic DNA was extracted both from freshly frozen brain tissue and from formalin fixed brain tissues to test the reliability of formalin fixed tissues as a source of genetic information. To confirm that the alleles observed in DNA extracted from fixed tissues showed Mendelian inheritance, we also investigated the segregation of alleles in an extended family with Familial Alzheimer Disease (FAD3) from

From the Division of Neurology, Department of Medicine, University of Toronto, and the Center for Research in Neurodegenerative Disease, University of Toronto, Toronto (M.M., G.V., P.H.S.G-H.); Department of Neurological and Psychiatric Sciences, University of Florence, Firenze, Italy (M.M.); Department of Neurology, University of Turin, Torino, Italy (G.V.).

RECEIVED NOVEMBER 10, 1993. ACCEPTED IN FINAL FORM JANUARY 14, 1994. Reprint requests to: P.H. St George-Hyslop, MD., Center for Research in Neurogenerative Diseases, Tanz Neuroscience Building, University of Toronto, 6 Queen's Park Crescent, Toronto, Ontario, Canada M5S IA8 
which pathologic samples have been collected from several deceased affected subjects whose spouses and/or offspring were also available. ${ }^{3,4}$ The primary genetic defect in this pedigree has recently been mapped to chromosome 14 near the marker D14S43. ${ }^{5}$

\section{Extraction of DNA from paraffin embedded tissue}

Two or three 10 micron sections were removed from the surface of a single paraffin block and discarded. Using a clean microtome, several additional 10 micron thick slices were collected either singly or in clusters of three sections in order to determine whether the quantity of initial starting material influenced the subsequent efficiency of polymerase change reaction (PCR) amplification. Both single sections (low concentration treatment) and clusters of three sections (high concentration treatment) were extracted twice in $1.0 \mathrm{ml}$ xylene at $23^{\circ} \mathrm{C} \mathrm{X} 30$ minutes each, and then re-extracted twice in $1.0 \mathrm{ml}$ absolute alcohol. The tissue residua were recovered by centrifugation, dried in a vacuum desiccator, broken up with a sterile pipette tip, re-suspended in $200 \mu \mathrm{l}$ TNE (10 mM Tris, $1 \mathrm{mM}$ EDTA, $100 \mathrm{mM} \mathrm{NaCl}$, pH 7.5), 0.5\% Tween 20 (Sigma), $400 \mu \mathrm{g} / \mathrm{ml}$ Proteinase $\mathrm{K}$ (Boehringer Mannheim) at $55^{\circ} \mathrm{C}$ for $18 \mathrm{~h}$, and finally extracted with phenol-chloroform $(1: 1)$ and chloroform. Because potential contaminants from the fixation and embedding processes might influence PCR amplification efficiency, we also investigated three different methods for recovering the genomic DNA from the digestion buffer for both the "low concentration" and the "high concentration" treatments above namely, ethanol precipitation; microfiltration on a Centricon 30 (MW cut-off $30 \mathrm{kD}$ ); or microfiltration on a Centricon $100 \mathrm{col}$ umn (MW cut-off $100 \mathrm{kD}$ ). The microfiltration steps were accomplished by diluting the digestion buffer to $2 \mathrm{ml}$ in sterile $\mathrm{H}_{2} \mathrm{O}$, concentration to $50 \mu \mathrm{l}$, followed by a second round of dilution and reconcentration to effectively accomplish the microdialysis. The DNA from each of the six "purification variants" from the same paraffin block was resuspended in $50 \mu \mathrm{l}$ sterile distilled $\mathrm{H}_{2} \mathrm{O}$ and stored at $-80^{\circ} \mathrm{C}$ without quantifying the amount of DNA recovered (previous work suggests that $A_{260}$ measurements on these specimens are frequently erroneous due to the presence of nucleic acid breakdown products and other contaminants ${ }^{6}$ ).

\section{PCR reactions}

Aliquots of DNA samples derived from each of the six purification variants from the same paraffin block were amplified using six published primer pairs which yield PCR amplimer products of 67-91 base pairs (bp) (D9S56/D9S12), ${ }^{7}$ 88-106 bp (D19S47), ${ }^{8}$ 106-122 bp (D I9S49), ${ }^{9}$ 123-143 bp (D9S110), ${ }^{10} 165-197$ bp (D9S55), ${ }^{11}$ and 195-209 bp (D9S15). ${ }^{12}$ PCR amplifications were carried out using annealing temperature and buffer conditions previously optimized for each set of primers using renewable sources of DNA. Typically, two microlitres of each template sample were amplified using 35 cycles in a final reaction volume of $20 \mu \mathrm{l}\left(1.5 \mathrm{mM} \mathrm{MgC}_{12}, 10\right.$ $\mathrm{mM}$ Tris pH 8.3, $50 \mathrm{mM} \mathrm{KCl,} 0.01 \%$ gelatin, $0.1 \%$ Triton $\mathrm{X}$ $100,200 \mu \mathrm{M}$ dNTPs, $10 \mathrm{pM}$ each primer, $0.75 \mu \mathrm{Ci}{ }^{32} \mathrm{P}$-dATP or ${ }^{32} \mathrm{P}-\mathrm{dCTP}$, and 0.6 units of Taq DNA Polymerase). The products were diluted 2 - 3 fold with formamide loading dye, denatured at $98^{\circ} \mathrm{C}$ for 5 minutes, and resolved according to size by electrophoresis on a $6 \%$ denaturing polyacrylamide gel. The genotype at each locus was determined for each individual from the number and size of the resultant autoradiographic bands.

\section{RESULTS}

Simple Sequence Repeat sequences were successfully amplified from 10 micron thick sections of paraffin embedded tissues; however the efficiency of this amplification was variable (Table 1). Previous studies have suggested that PCR amplification of DNA from fixed tissues was inhibited by contaminants co-purified with the template DNA and recommended low concentrations of initial starting material (usually a single 10 micron section). However, we observed that PCR targets of less than 150 bp (D9S56, D19S47, D19S49 and D9S110) showed consistently successful amplification of both alleles regardless of preparative technique or quantity of starting material. Conversely, inconsistent amplification was observed (3 out of 6 trials) for primer pairs with amplification products greater than 165 bp (D9S55 and D9S15). The efficiency of amplification for primers with larger amplimers (D9S55 and D9S15) was not related to the method of template preparation or amount of starting material (Table 1).

Amplification of six separately extracted sections from the same tissue block generated identical genotype information on all trials for D9S56, D19S47, D19S49 and D9S110, indicating that the amplification results are reproducible. Furthermore no differences were observed between genotypes assessed using DNA from frozen tissue sources and those determined using formalin fixed tissue specimens from the same subject. More importantly, we were able to show Mendelian inheritance of alleles for the D9S110 and D9S55 loci in an extended pedigree (Figures $1 \mathrm{a}$ and $\mathrm{lb}$ respectively).

\section{Discussion}

Our results demonstrate the feasibility of using formalin fixed, paraffin embedded neurological tissue samples as a source of template DNA for genetic analyses using PCR based SSR polymorphisms. Although previous studies have suggested that contaminants in the extractate may inhibit PCR

Table 1. Factors Potentially Affecting PCR Amplification Efficiency.

\begin{tabular}{lccccccc}
\hline & & \multicolumn{7}{c}{ DNA Preparation Method } \\
\cline { 3 - 8 } LOCUS & $\begin{array}{l}\text { SIZE } \\
\text { ID }\end{array}$ & $\mathbf{1}$ & $\mathbf{2}$ & $\mathbf{3}$ & $\mathbf{4}$ & $\mathbf{5}$ & $\mathbf{6}$ \\
\hline D9S56 & $67-97$ & + & + & + & + & + & + \\
D19S47 & $88-106$ & + & + & + & + & + & + \\
D19S49 & $106-112$ & + & + & + & + & + & + \\
D9S110 & $123-143$ & + & + & + & + & + & + \\
D9S55 & $165-197$ & + & - & + & - & - & + \\
D9S15 & $195-209$ & - & + & - & + & + & -
\end{tabular}

The effect of the method of DNA preparation (Column $1=$ Ethanol precipitation, single section; Column $2=$ Ethanol precipitation, three sections; Column $3=30 \mathrm{kD}$ microfiltration, single section; Column 4 $=30 \mathrm{kD}$ microfiltration, three sections; Column $5=100 \mathrm{kD}$ microfiltration, single section; Column $6=100 \mathrm{kD}$ microfiltration, three sections), and of PCR product size on reliability of PCR amplification of SSR sequences are examined. Results are depicted as $(+)=$ specific amplification of both alleles; $(-)=$ non-specific amplification or no amplification. Loci with high molecular weight PCR products (> 165 bp) were less reliably amplified than sequences with lower molecular weight products. 


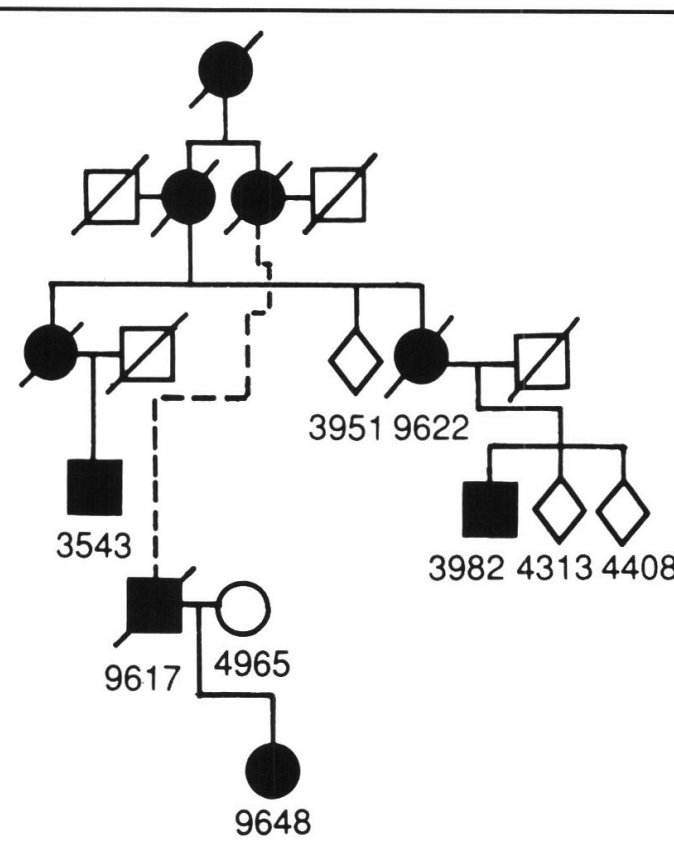

$\begin{array}{llllllllll}\text { LANE\# } & 1 & 2 & 3 & 4 & 5 & 6 & 7 & 8 & 9\end{array}$

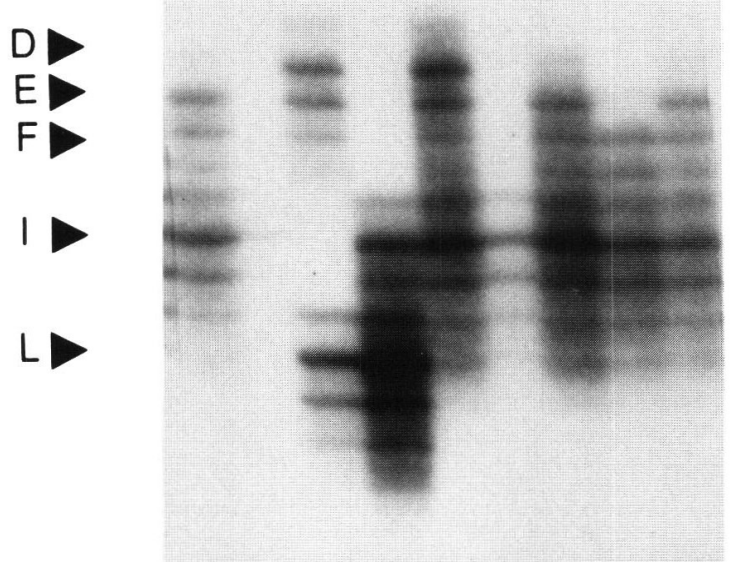

D9S110 EI \| DL ILDI ॥ EI FI EI TYPE

Figure 1a: Oligonucleotide primer pairs for the D9S110 locus were used to amplify DNA from 10 micron paraffin sections from two deceased subjects (lane 2: 9617; lane 6: 9622) and DNA from buffy coat leukocytes from their other living affected and unaffected relatives (lane 1: 3543; lane 3: 4965; lane 4: 9648; lane 5: 3951; lane 7: 3982; lane 8: 4313; lane 9: 4408). The genotype of each individual is depicted below the autoradiogram. Mendelian patterns of inheritance of alleles are observed. Filled symbols in the pedigree diagram represent individuals affected with familial Alzheimer Disease. A complete diagram of this pedigree has been published elsewhere. ${ }^{3.5}$

amplification, ${ }^{6}$ we observed that the major limiting factor for reliable amplification of SSR sequences from fixed neurologic tissues is the size of the PCR target to be amplified (targets greater than $165 \mathrm{bp}$ in size were not amplified on all trials). The small size of the target sequences which could be reliably amplified from fixed neurologic tissues is in sharp contrast to other studies which have reported successful PCR amplification

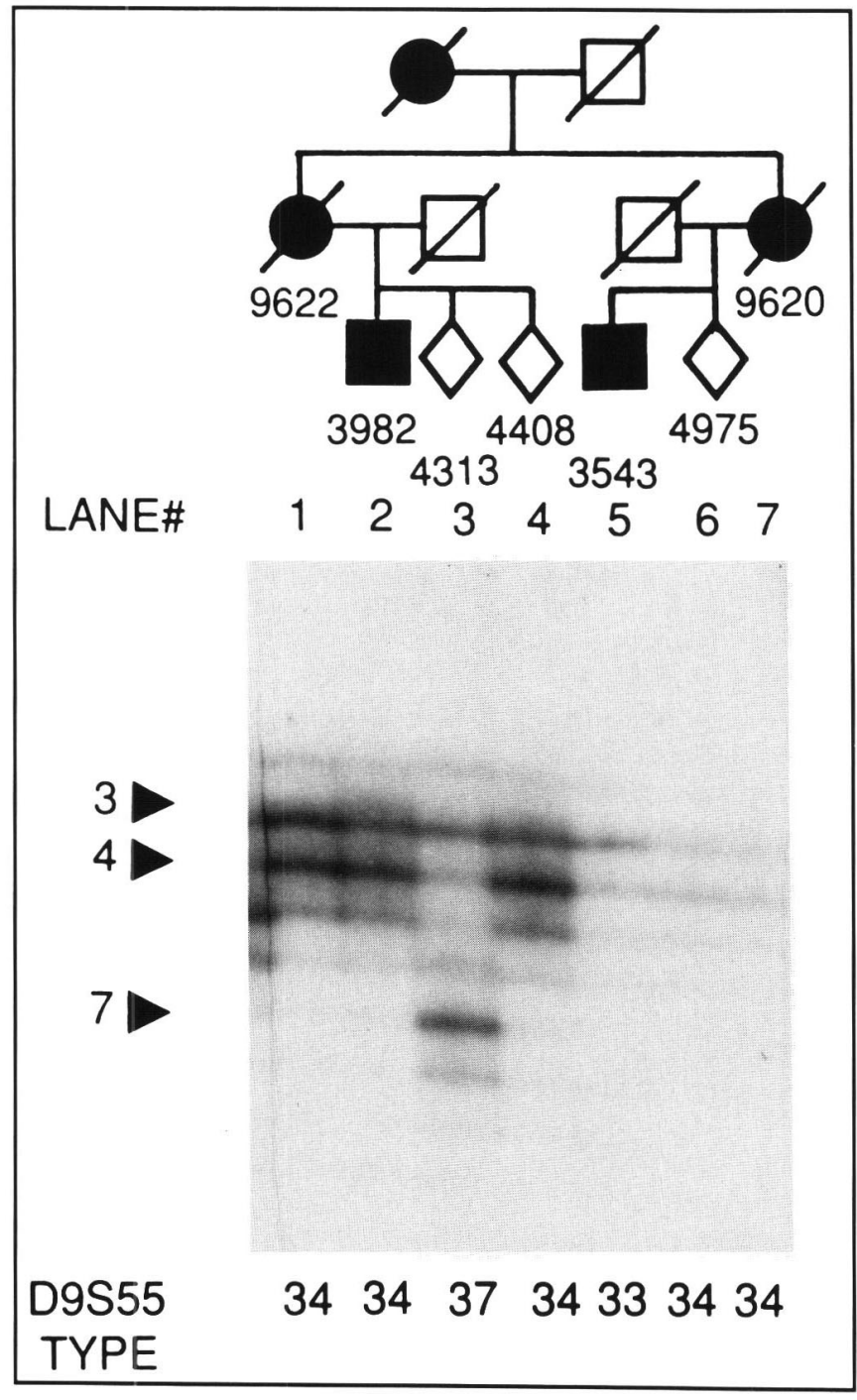

Figure 1b: Published oligonucleotide primer pairs for the D9S55 locus were used to amplify DNA from 10 micron paraffin sections from two deceased subjects (lane 1: 9622; lane 7: 9620) and DNA from buffy coat leukocytes of their respective living affected and unaffected offspring (lane 2: 3982; lane 3: 4313; lane 4: 4408; lane 5: 3543; lane 6: 4975).

of sequences up to $1 \mathrm{~kb}$ in length from fixed tissues. ${ }^{6,13}$ The smaller size of amplifiable targets reported here probably arises from two sources. First, previous studies have examined the amplification of non-repetitive sequences. Amplification of SSR sequences is often more difficult, being complicated by constraints on the choice of optimal PCR primers near the SSR sequence and by other technical problems such as "slippage" of the DNA polymerase during amplification of the SSR sequence, etc. ${ }^{8}$ Second, previous studies (refs. 6 and 13) have used nonneurologic tissues which are typically fixed in formalin for 12 24 hours. In comparison, neurologic tissues are typically fixed for at least seven days. This difference in fixation procedures is likely to be important because prolonged fixation in formalin significantly reduces the size of amplifiable products from 989 bp after 72 hours of fixation to 268 bp after 30 days of fixation. ${ }^{13}$ One other study examining the amplification of single copy, non-repetitive templates from formalin fixed neurologic 
tissues also reported difficulty in amplification of templates of more than $300 \mathrm{bp}$ in size. ${ }^{14}$ We do not think that the small size of the PCR templates which could be reliably amplified from formalin fixed neurologic tissues reflect an artifact peculiar to the markers we have used because the markers we chose are representative of most other microsatellite loci in terms of nucleotide composition and $\mathrm{Tm}$ of the oligonucleotide primers and GC content of the sequences surrounding the microsatellite array.

The size constraints imposed by the nature of the target sequence and by the source of tissues typically available for the analysis of inherited neurologic diseases will require careful selection of genetic markers to be used for the analysis of fixed tissues from deceased members of such pedigrees. Optimally, such markers should have PCR products close to or below 165 bp in size. Markers with PCR products above this size obviously may still be used because microsatellite markers do differ in the ease with which they can be amplified and scored. However, our results suggest that they may have a higher failure rate, which will result in wastage of a non-renewable resource. Furthermore, if markers with PCR products of a higher molecular weight are employed, it will be important to bear in mind the theoretical possibility that high molecular weight alleles may not be amplified as well as lower molecular weight alleles. Under these circumstances heterozygotes may appear to be homozygous for the low molecular weight allele. While we draw attention to this caveat, we do not preclude the use of markers with allele sizes greater than $165 \mathrm{bp}$, but we do suggest cautious interpretation of the results. Indeed, we have been able to generate useful data for the D9S55 locus with amplimers between 165 and 197 bp in one family (Figure $1 b$ ) even though this same locus could not be amplified from three of six other specimens.

In addition to these caveats, four other practical considerations must also be borne in mind. First, the accuracy of the archival source of pathological tissues needs to be assured. Second, pathologic tissue specimens are usually handled by multiple personnel, and great care must therefore be exercised to minimize the possibility of amplification of contaminant sequences. This objective can most easily be achieved by using a different, clean microtome to cut each tissue block, and by discarding the first few sections cut from the surface of a new block. Third, the putative clonal nature and genomic instability of some tumours, ${ }^{15-17}$ argues that where possible sections should be used from tumour free zones. Finally, the PCR products generated from fixed tissue templates are rarely as pure as those generated from conventional sources, and as a result autoradiographs frequently contain minor spurious bands. This might be minimized by using two rounds of amplification with a second set of internal primers.

\section{REFERENCES}

1. McKusick VA. Mendelian Inheritance in Man. 1992, Baltimore: Johns Hopkins University Press.

2. St George-Hyslop PH, Myers RH, Haines JL, et al. Familial Alzheimer's Disease: progress and problems. Neurobiol Aging 1989; 10: 417-425.

3. St George-Hyslop PH, Tanzi RE, Polinsky RJ, et al. The genetic defect causing Familial Alzheimer Disease maps on chromosome 21 . Science $1987 ; 235: 885-889$.

4. Pollen D. Hannah's Heirs: the quest for the genetic origins of Alzheimer's disease. 1993, Oxford: Oxford University Press.

5. St George-Hyslop P, Haines J, Rogaev E, et al. Genetic evidence for a novel Familial Alzheimer Disease gene on chromosome 14. Nature Genet 1992; 2: 330-334.

6. Wright DK, Manos MM. Sample preparation from paraffin-embedded tissues. In: Innis MA, et al., ed. PCR Protocols: A Guide to Methods and Applications. San Diego: Academic Press, 1990: 153-158.

7. Kwiatkowski, DJ, Henske, EP, Weimer, K, et al. Construction of a GT polymorphism map of human 9q. Genomics 1992; 12: 229 240.

8. Weber JL, May PE. Abundant class of human DNA polymorphisms which can be typed using the polymerase chain reaction. Am J Hum Genet 1989; 44: 388-396.

9. Weber JL, May PE, Kappel C. Dinucleotide repeat polymorphisms at the D19S49 locus. Nucl Acid Res 1990; 18: 1927.

10. Fujita R, Sirugo G, Duclos F, et al. A $530 \mathrm{~Kb}$ YAC contig tightly linked to the Freidreich's Ataxia Locus contains five CpG clusters and a new highly polymorphic microsatellite. Hum Genetics 1992; 89: 531-538.

11. Sharma V, Brown D, Smith L, Magenis RE, Litt M. Dinucleotide repeat polymorphism at the D9S55 locus. Nucl Acid Res 1991; 19: 4023.

12. Wallis $\mathrm{J}$, Williamson $\mathrm{R}$, Chamberlain $\mathrm{S}$. Identification of a hypervariable microsatellite polymorphism within D9S 15 tightly linked to Freidreich's Ataxia. Hum Genetics 1990; 85: 98-100.

13. Greer CE, Lund J, Manos MM. PCR amplification from paraffinembedded tissues: recommendations on fixatives for long term storage and prospective studies. PCR Meth Applications 1991; 1: 46-50.

14. Karlinsky H, Vaula G, Haines JL, et al. Molecular and prospective phenotypic characterization of a pedigree with familial Alzheimer Disease and a missense mutation in codon 717 of the B-amyloid precursor protein (APP) gene. Neurology 1992; 42: 1445-1453.

15. Seizinger BR, Martuza RL, Rouleau G, Breakfield XO, Gusella JF. Models for inherited susceptibility to cancer in the nervous system: a molecular-genetic approach to neurofibromatosis. Dev Neurosci 1987; 9: 144-153.

16. Cavanee WK, Dryja TP, Phillips RA, et al. Expression of recessive alleles by chromosomal mechanisms in retinoblastoma. Nature 1983; 305: 779-784.

17. Cottrell S, Bicknell D, Kaklamanis L, Bodmer WF. Molecular analysis of APC mutations in familial adenomatous polyposis and sporadic colon carcinomas. Lancet 1992; 340: 626-630. 